\title{
Distribution and Phosphorylation of the Growth-Associated Protein GAP-43 in Regenerating Sympathetic Neurons in Culture
}

\author{
K. F. Meiri, ${ }^{a}$ M. Willard, and M. I. Johnson ${ }^{1}$ \\ Department of Anatomy and Neurobiology, and 'Departments of Pediatrics and Neurology, Washington University School \\ of Medicine, St. Louis, Missouri 63110
}

\begin{abstract}
Sympathetic neurons regenerating in culture were studied in order to gain further insight into the intracellular distribution and phosphorylation of GAP-43, a protein that has been suggested to have a role in axonal outgrowth and neuronal plasticity (Willard et al., 1987). Superior cervical ganglion neurons from embryonic rats were highly reactive with a polyclonal antibody against the growth-associated protein GAP-43 soon after they were placed in culture on a laminin substrate. As these neurons extended neurites, the distribution of GAP-43 reactivity changed. The cell body became progressively less reactive, whereas the growth cone at the tip of the growing neurite reacted strongly. The pattern of immunofluorescence was punctate both in the growth cone and the adjacent neurite, but appeared more diffusely distributed in the cell body. The antibody reacted only with cells that had been subjected to treatment that permeabilized the plasma membrane. When antibody was supplied in the medium of growing neurons, it neither bound to the cells nor altered normal neurite initiation or elongation. Of the different types of cells in these cultures, the antibody reacted only with neurons; It did not react with Schwann cells or fibroblasts. The stimulation of protein kinase $C$ in these cultures resulted in a 7-fold stimulaton of the phosphorylation of a protein of similar electrophoretic mobility to GAP-43. These observations demonstrate that GAP-43 is neuron-specific, is present throughout the neuron but at higher levels in the growth cone, and is a major substrate of protein kinase $C$. The high concentration of GAP-43 in the growth cones may necessitate its increased synthesis in neurons with elongating axons. Its location and phosphorylaton by kinase $\mathrm{C}$ suggest that it could perform a function in the growth cone that is modulated by extracellular signals, such as those used in pathfinding or in the control of axonal elongation.
\end{abstract}

During target-directed axonal outgrowth, when the nervous system is developing, or when a neuron is regenerating following injury, the growing axon elaborales a prominent, growth-specific

\footnotetext{
Received Aug. 21, 1987; revised Nov. 27, 1987; accepted Nov. 27, 1987.

We are grateful for the careful and helpful review of this manuscript by Drs. Mary B. Bunge and Paul C. Bridgman; the technical assistance of Rob Soriano, Arlene Loewy, and Joe Hayes; and the secretarial expertise of Sue Eads. Dr. Nancy Ratner provided the cultures of purified Schwann cells. The $217 \mathrm{c}$ antibody was a gift of Dr. J. de Vellis. The work was supported by NIH Grants EY06082 (K.F.M. and M.W.) and NS21771 (M.I.J.), NSF Grant BNS 8508148 (M.I.J.), and a McKnight Foundation grant (M.W.).

Correspondence should be addressed to Dr. Mary I. Johnson, Department of Anatomy \& Neurobiology, Washington University School of Medicine, 660 South Euclid Avenue, St. Louis, MO 63110.

${ }^{2}$ Present address: Department of Pharmacology, SUNY Health Science Center, 750 East Adams Street, Syracuse, NY 13210

Copyright (C) 1988 Society for Neuroscience $0270-6474 / 88 / 072571-11 \$ 02.00 / 0$
}

structure at its leading edge. This "growth cone" is able to translocate over a substrate and to make synaptic contacts with appropriate target neurons, and is highly specialized to perform a number of functions (for review, see Johnston and Wessels, 1980; Bunge et al., 1983, 1987; Landis, 1983; Kater and Letourneau, 1985; Letourneau, 1985), including those of motility (see, for example, Letourneau, 1975; Tosney and Wessels, 1983; Argiro et al., 1984; Bray and Chapman, 1985), pathfinding (Bastiani and Goodman, 1986; Bentley and Toroian-Raymond, 1986; Caudy and Bentley, 1986; Kuwada, 1986), adhesion to the substrate (Letourneau, 1975; Hammarback and Letourneau, 1986), and membrane addition (Bray, 1970, 1973; Pfenninger and Maylie-Pfenninger, 1981a, b; Pfenninger and Johnson, 1983). Growth cone morphology has been described both in fixed preparations (Ramon y Cajal, 1890; Yamada et al., 1971; Bunge, 1973) and in the living state (Harrison, 1907; Pomerat et al., 1967; Letourneau, 1975; Tosney and Wessels, 1983; Argiro et al., 1984). Growth cones include a basal area from which highly motile lamellipodia and/or filopodia are extended into the surrounding environment. The molecular mechanisms that control growth cone formation and that regulate its function are unknown.

A potential clue is that certain proteins, designated growthassociated proteins, or GAPs, are much more abundant in neurons with growing axons than in neurons where synaptic connections have already been established, suggesting that they may perform functions required at much higher levels during axonal growth. One of these, GAP-43, a phosphopeptide with a molecular weight of $24 \mathrm{kDa}$ (Basi et al., 1987; Karns et al., 1987), is synthesized and axonally transported at elevatcd lcvels during both developmental and regenerative axonal growth (Skene and Willard, 1981a, b). Subcellular fractionation and immunocytochemical experiments have demonstrated that GAP-43 is a principal component of the growth cone, and is highly enriched there (Meiri et al., 1986; Skene et al., 1986). The function of GAP-43 is unknown; however, in vitro GAP-43 (which is very similar or identical to the proteins designated B50, pp46, and F1) is a substrate for protein kinase C (Aloyo et al., 1983; Akers and Routtenberg, 1985; Meiri and Willard, 1986; Willard et al., 1987), which suggests that its function may be modifiable by phosphorylation.

In order to gain further insight into the function of GAP-43 in growing neurons, we have studied sympathetic neurons regenerating in culture, where the kinetics of neurite outgrowth have been well-defined and correlated with the morphology of growth cones of neurons from different-aged animals. We have used this system to determine (1) how GAP-43 is distributed in the neurons; (2) whether the presence and hence the function of GAP-43 is necessary only in neurons, or is a component of 
othcr motile cell types, such as the fibroblasts present in these cultures; (3) whether GAP-43 is induced before neurite outgrowth is initiated, and hence may be in a position to regulate it, or whether it is evident only after neurites have begun to grow; (4) whether the GAP-43 antigens are exposed on the surface of living neurons, and whether the behavior of the growing neurites could be perturbed by an antibody to GAP-43; and (5) whether the phosphorylation of GAP-43 is stimulated when kinase $C$ is activated. We discuss the results of these experiments in relationship to the possible role of GAP-43 in the process of neurite outgrowth.

\section{Materials and Methods}

\section{Preparation of cultures}

The procedures for the dissection and preparation of explants or dissociated neurons from rat superior cervical ganglia (SCGs) have been described previously (Johnson and Argiro, 1983). Briefly, ganglia were dissected from 20 or $21 \mathrm{~d}$ embryos, the connective tissue capsules removed, and small, $1 \mathrm{~mm}$ explants prepared. When dissociated neurons were required, the explants were incubated in $0.25 \%$ trypsin in L15 Leibovitz medium (Grand Island Biologicals, Grand Island, NY), rinsed, and then triturated in medium ( $10 \%$ human placental serum, $2 \%$ embryo extract, $600 \mathrm{mg}$ glucose, $2 \mathrm{~mm}$ glutamine, and $25 \mathrm{U} / \mathrm{ml}$ NGF). Explants or dissociated cell suspensions were plated onto $12 \mathrm{~mm}$ coverslips (\#1; Bellco Glass, Vineland, NJ) that had previously been coated with collagen or laminin. The collagen was prepared by acid extraction and was applied as previously described (Johnson and Argiro, 1983). Laminin (Collaborative Research, Bedford, MA) was dissolved to $16.6 \mu \mathrm{g} /$ $\mathrm{ml}$ in $0.1 \mathrm{M}$ carbonate buffer ( $\mathrm{pH} 7.8$ ). The coverslips were incubated overnight at $35^{\circ} \mathrm{C}$ with $0.2 \mathrm{ml}$ of the laminin solution, rinsed 5 times in $\mathrm{L} 15$ medium, and the final rinse replaced with medium (see above). Most of the experiments reported here used laminin-coated coverslips, as, unlike even dilute collagen, which produced a 3-dimensional substrate, the laminin afforded better visualization of the growth cones, which were primarily 2 -dimensional.

\section{Purification of GAP-43 and affinity purification of anti-GAP-43}

GAP- 43 was purified to homogeneity from postnatal day 1 rat forebrains by selectively solubilizing the membranes in SDS and then separating the extracted proteins by reverse-phase high-performance liquid chromatography (HPLC) (F. Meiri and M. Willard, unpublished observations). A rabbit was immunized with pure GAP-43, as described previously (Meiri et al., 1986), and the antibody against GAP-43 was affinity-purified from the serum by one of 2 methods. In the first, affinitypurified antibody was eluted from nitrocellulose paper to which GAP. $43 \mathrm{had}$ been bound, and which had been incubated with the anti-GAP43 antiserum (Talian et al., 1984). In the second method, pure GAP43 , prepared as above, was covalently linked to Sepharose 4B with cyanogen bromide (Wilchek et al., 1984) and used in a column over which the antiserum was passed. The column was washed in PBS (50 $\mathrm{mm}$ Tris, $150 \mathrm{~mm} \mathrm{NaCl}, \mathrm{pH}$ 7.4). Antibody that had specifically bound to the column was eluted with $0.1 \mathrm{M}$ glycine ( $\mathrm{pH} 2.4$ ) and subsequently dialyzed against PBS. Either purification technique yielded affinity-purified antibody that reacted specifically with GAP-43 when it was analyzed by 2 -dimensional Western blotting.

\section{Immunocytochemistry}

Fixed cultures. Explants or dissociated cells that had grown 1-6 d in culture were fixed in $4 \%(\mathrm{wt} / \mathrm{vol})$ paraformaldehyde in $0.1 \mathrm{~m}$ phosphate

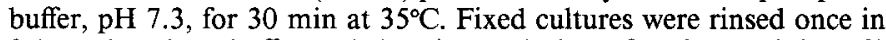
$0.1 \mathrm{~m}$ phosphate buffer and then in a solution of PBS containing $5 \%$ (vol/vol) goat serum (PBS-5\% goat serum). We originally used either $0.05 \%$ SDS or $0.1 \%$ saponin in PBS- $5 \%$ goat serum to permeabilize cultures before immunocytochemistry (Meiri et al., 1986), but because $0.01 \%$ digitonin in PBS-5\% goat serum produced optimal results, this was used in the experiments reported here. Fixed cultures were permeabilized for $30 \mathrm{~min}$ in $0.01 \%$ digitonin in PBS-5\% goat serum, incubated for $1 \mathrm{hr}$ in affinity-purified anti-GAP-43 $(6 \mu \mathrm{g} / \mathrm{ml})$ in PBS-20\% goat serum, and rinsed 3 times for 5 min each in PBS-5\% goat serum. Bound antibody was visualized with affinity-purified, fluorescein-labeled goat anti-rabbit IgG (Cappell, West Chester, PA), which was centrifuged in an airfuge at 30 psi for $10 \mathrm{~min}$ before use. Cultures were incubated for $1 / 2 \mathrm{hr}$ in the secondary antibody at a dilution of $1: 100$ in PBS-20\% goat serum, then rinsed 3 times for 5 min each in PBS-5\% goat serum and mounted in Citifluor (City University, London, UK) anti-bleach mountant.

Sister cultures used as controls were not treated with anti-GAP-43, but instead were incubated either in PBS-5\% goat serum or with nonimmune rabbit IgG. Subsequent rinses, incubation in the goat antirabbit secondary, and mounting were identical. In early experiments, cultures treated with anti-GAP-43 but no secondary antibody were also included as controls. Initial experiments included some cultures fixed in paraformaldehyde but not permeabilized.

Surface membrane labeling of explants. In some experiments, cultures grown 1-2 $\mathrm{d}$ in vitro were incubated with affinity-purified anti-GAP-43 antibody prior to fixation. In these experiments, the cultures were not made permeable, and the antibody was used at a concentration of $6 \mu \mathrm{g} /$ $\mathrm{ml}$ in medium containing $10 \%$ human placental serum that had been heat-inactivated, and $0.02 \%$ sodium azide, which was included to prevent endocytosis of any antigen-antibody complex. As a positive control, sister cultures (also unfixed) were reacted with the antibody A2B5, which recognizes a surface ganglioside on neuronal membranes (Eisenbarth et al., 1979). A2B5 immunoreactivity was visualized with an affinity-purified, rhodaminated goat anti-mouse IgG (Cappell), prepared and used as described for the fluoresceinated secondary antibody. In these experiments, cultures were rapidly rinsed and fixed, as described above, immediately after incubation with the primary antibody. In separate experiments, explants were grown for up to $7 \mathrm{~d}$ in the presence of anti-GAP-43 at concentrations between 6 and $60 \mu \mathrm{g} / \mathrm{ml}$ in medium containing $10 \%$ heat-inactivated human placental serum. The antibody was added either at the time of initial placement of the explants in culture or $24 \mathrm{hr}$ later. As controls, explants were grown for similar time periods in either PBS, nonimmune IgG, or the antibody A2B5. The medium was changed daily for the duration of the experiment. The extent of neurite outgrowth was measured as previously described (Argiro and Johnson, 1982).

Double-labeling of non-neuronal cells. In the experiments to determine whether the anti-GAP-43 antibody reacted with non-neuronal cells, Schwann cells were identified with the antibody $217 \mathrm{C}$ (Peng et al., 1982) and fibroblasts were identified by anti-Thy-1.1 immunoreactivity (Marshak-Rothstein et al., 1979). Fibroblasts were obtained by establishing SCG explants in culture, as described above. After several days, the central mass of tissue containing the neurons was cut out, leaving a population of non-neuronal cells, including fibroblasts and Schwann cells. Schwann cells in pure population were prepared as described previously (Porter et al., 1986) and were a gift from Dr. Nancy Ratner. Immunohistochemistry was performed as described for the previous experiments, except that the cultures were fixed and made permeable only after treatment with $217 \mathrm{C}$ (a gift from J. de Vellis) or anti-Thy-1.1 (American Type Culture Collection, Rockville, MD) and prior to incubation with the anti-GAP-43 antibody.

\section{Labeling of phosphoproteins in cultured superior cervical ganglia}

Dissociated SCG cells were grown for several days in culture, as described above, before their medium was replaced with L15 medium containing $2 \mathrm{mCi} / \mathrm{ml}^{32} \mathrm{P}$ orthophosphate. After $1 \mathrm{hr}$ of incubation with ${ }^{32} \mathrm{P}, 10 \mathrm{nM}$ phorbol 12 -myristate 13-acetate $(\beta$-PMA) dissolved in dimethyl sulfoxide (DMSO) was added to some cultures to stimulate kinase $C$ activity. Controls received either $10 \mathrm{nM} 4 \alpha$-phorbol 12,13didecanoate ( $\alpha$-PMA), which does not stimulate kinase $\mathrm{C}$, or an equal volume of DMSO. After $10 \mathrm{~min}$ incubation with either $\beta$-PMA or $\alpha$-PMA, the cultures were washed 3 times with ice-cold L15 medium, and the cells harvested by scraping the plates with a rubber policeman. To prepare protein for analysis by 2-dimensional SDS-PAGE, a particulate fraction was prepared from the cultures by centrifuging them in an airfuge at $30 \mathrm{psi}$ for $30 \mathrm{~min}$. The proteins from this fraction were solubilized in $0.5 \%$ SDS and the protein concentration determined using Coomassie blue R-250 (Ranscht et al., 1984). Solubilized protein was separated on 2-dimensional SDS-PAGE as described previously (Meiri et al., 1986). The Coomassie blue-stained gels were dried and exposed to a Kodak X-AR film with a Cronex fluorescent intensifier screen. 


\section{Results}

Localization of GAP-43 in sympathetic neurons

Expression of GAP-43 immunoreactivity precedes neurite extension. When dissociated E21 SCGs are cultured, neurite regeneration is generally initiated within $24 \mathrm{hr}$, but asynchronously. When cells that had grown between 12 and $24 \mathrm{hr}$ in culture were fixed, permeabilized, and incubated with anti-GAP-43 antibody, those cells that had attached to the substrate, but had not yet begun to grow neurites, appeared intensely immunofluorescent (Fig. 1a). Similarly, the somata and short neurites of neurons from the same culture, which had just begun to extend processes, fluoresced brightly (Fig. $1 b$ ). In cells that had longer neurites ( $>100-200 \mu \mathrm{m})$, staining of the cell bodies was markedly less intense than that in cells with neurites $<100 \mu \mathrm{m}$ or where outgrowth had not yet begun (Fig. $1 c$ versus Fig. 1, $a, b$ ).

GAP-43 appears most concentrated in the growth cone. In neurons with longer neurites, the growth cones often fluoresced as intensely as the cell bodies, even though the volume of the growth cones was much less than that of the cell body (Fig. 2), suggesting that, as the neurite elongates, the concentration of GAP-43 antigen in the growth cones changes relative to the concentration of antigen in the cell bodies. This apparent gradient was observed both in dissociated cultures (Fig. 2, $a, b$ ) and explant cultures (Fig. 2, $c-e$ ). These results indicate that while the antigens recognized by the anti-GAP-43 antibody are present throughout the neuron, they are most concentrated in the neuronal growth cone.

Pattern of anti-GAP-43 immunoreactivity. After $24 \mathrm{hr}$ in culture on a laminin substrate, neurites from either explants or dissociated cells had growth cones with complex morphologies (Fig. 3). In most cases these growth cones appeared 2-dimensional and had extensive membrane expansions and numerous filopodia (Fig. 3). In 3 separate explant experiments, we compared the phase and fluorescent images of over 200 growth cones at high magnification under oil $(100 \times$, n.a. 1.25; Zeiss). All of the growth cones we observed reacted with the antibody, including the entire extent of the filopodia. The labeling with the antibody was punctate around the perimeter of the growth cone, in the main body of the growth cone, and in the filopodia (Fig. $3, a-c)$. In neurites adjacent to the growth cones, fluorescence appeared to be increased at the plasma membrane and also had a punctate appearance (Fig. $3 a$, arrowheads). Additionally, many varicosities present along the neurites often fluoresced brightly. In contrast to the punctate pattern in the distal neurite and growth cone, the immunoreactivity in the somata of dissociated neurons showed less intense fluorescence, and the staining was more diffuse even under high magnification (Figs. $1 c, 2 a$ ). Within somata, fluorescence was most concentrated in the perinuclear area (Figs. 1c, 2a).

Anti-GAP-43 reacts with intracellular antigens but not with the cell surface. When SCGs were fixed with $4 \%$ paraformaldehyde but not permeabilized prior to incubation with antiGAP-43 antibody, faint immunofluorescence was detected in the cell bodies and neurites (results not shown). This low level of staining was not seen when cultures were incubated with an equivalent concentration of nonimmune IgG (Fig. $4, e, f$ ). Specific anti-GAP-43 immunoreactivity was dramatically intensified if the fixed cultures were made permeable by treatment with $0.01 \%$ digitonin before incubation with antibody (Figs. 1-3).

To investigate whether GAP-43 antigens are exposed on the surface of neurons, living cultures of explants from SCGs were
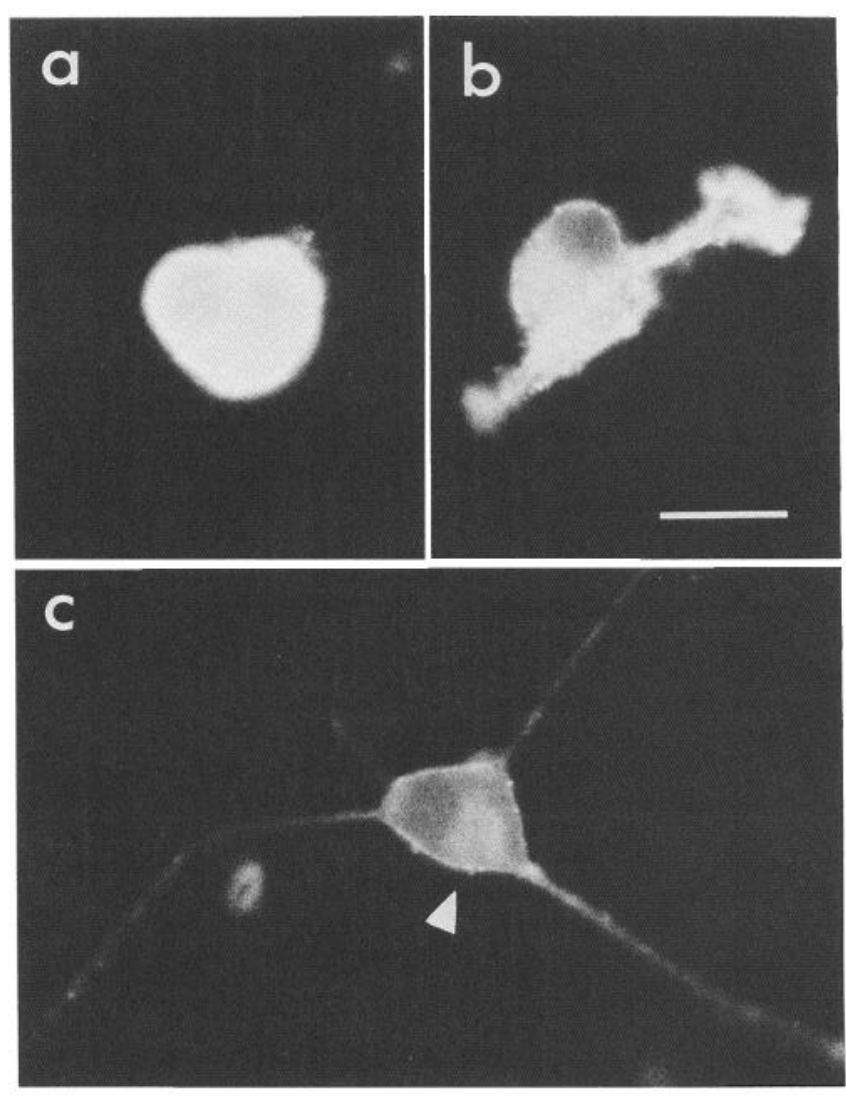

Figure 1. Dissociated SCG neurons after $18 \mathrm{hr}$ in vitro. a, Fluorescent photomicrograph of a dissociated SCG neuron that has not yet extended neurites demonstrates intense anti-GAP-43 immunoreactivity within the soma. The nucleus, left, is obscured. $b$, Fluorescent photomicrograph obtained from the same culture used in $a$, showing a dissociated neuron that has extended short neurites. The cell is still quite fluorescent, but the nucleus is now apparent. $c$, Fluorescent photomicrograph of another neuron from the same culture. The neurites are $200 \mu \mathrm{m}$ or greater in length. In this case the neuronal soma is less fluorescent than either $a$ or $b$ and shows a perinuclear concentration of immunoreactivity ( $a r$ rowhead). All the neurons were growing on the same coverslip, within $300-400 \mu \mathrm{m}$ of each other, and therefore experienced identical fixation, permeabilization, and staining conditions. In addition, they were photographed and printed identically. Bar, $20 \mu \mathrm{m}$.

incubated for $1 \mathrm{hr}$ with anti-GAP-43 that had been added to the culture medium. When these cultures were subsequently fixed, they did not react with a fluorescently labeled secondary antibody, indicating that the anti-GAP-43 antibody had not bound to the surface of the living neurons (Fig. $4, c, d$ ). In contrast, when the cultures were incubated with the antibody A2B5, which recognizes a ganglioside epitope on the surface of neuronal membranes, the neurites were labeled with A2B5 (Fig. $4, a, b)$. The growth cones were stained with A2B5 only if sodium azide was included in all the steps before fixation to inhibit endocytosis of the antigen-antibody complex at the growth cone. The presence of sodium azide did not alter the inability of antiGAP-43 to react with these living cultures.

Explants grown continuously in anti-GAP-43 antibody-containing culture medium for up to $7 \mathrm{~d}$ (Fig. 5) were compared with explants grown in medium to which either buffer (PBS), nonimmune IgG, or A2B5 (data not shown) had been added as a control (Table 1). We did not detect any differences in either the onset of initiation of neurites or the extent of neurite out- 


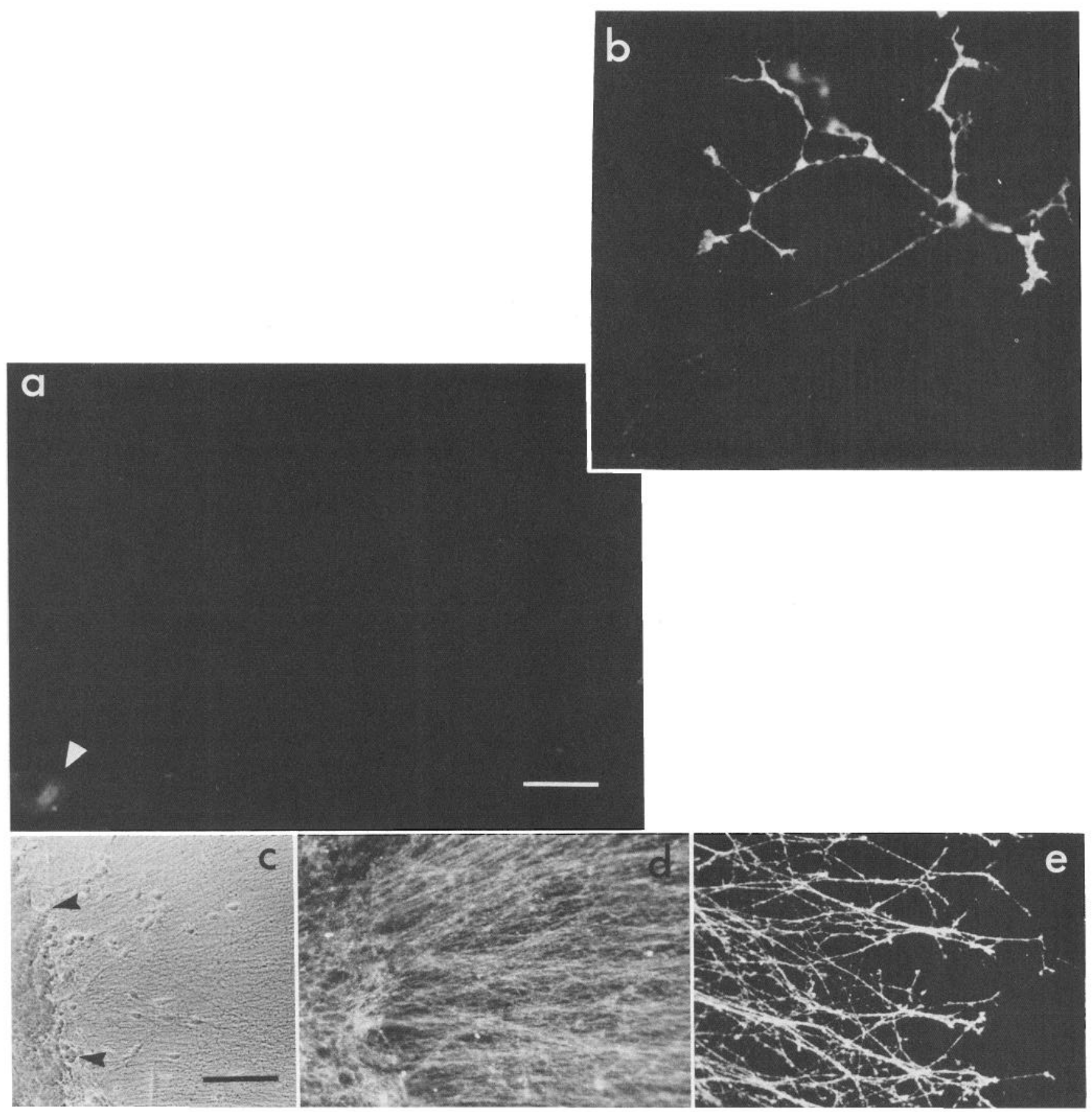

Figure 2. GAP-43 is concentrated at the growth cone of dissociated and explanted SCG neurons. $a, b$, A dissociated SCG neuron after $1 \mathrm{~d}$ in vitro. Fluorescent photomicrograph of the neuron showing that the soma $(a)$ is less intensely fluorescent than the arbor of growth cones at the terminal end of one of its neurites $(b)$. Within the soma anti-GAP-43 immunoreactivity appears most concentrated in the perinuclear area (arrowhead in $a$ ). $c-e$, An explant culture after $5 \mathrm{~d}$ in vitro. Phase-contrast micrograph near the explant $(c)$, viewed with fluorescence microscopy, demonstrates that the neurites adjacent to the explant $(d)$ appear less fluorescent than those at the growth cone front $(e)$. The edge of the explant is indicated with arrowheads $(c)$. Bar, $20 \mu \mathrm{m}(a, b) ; 100 \mu \mathrm{m}(c-e)$.

growth between these groups of cultures, even when anti-GAP43 antibody was applied at concentrations up to $60 \mu \mathrm{g} / \mathrm{ml}$, or 10 -fold that used for immunohistochemistry. GAP-43, therefore, does not appear to have an extracellular function that can be perturbed by this antibody. These results, and the inability of anti-GAP-43 to bind to the outside of living cells, suggest that the epitopes recognized by the anti-GAP- 43 antibody are intracellular. Thus, only when the neurons were made perme- able did anti-GAP-43 react strongly with the somata, neurites, and growth cones of explants or dissociated SCG neurons (Figs. $1-3)$.

\section{Anti-GAP-43 antibody does not react with Schwann cells or fibroblasts}

When SCG explants were cultured, anti-GAP-43 antibody reacted only with the neurons and not with non-neuronal cells 


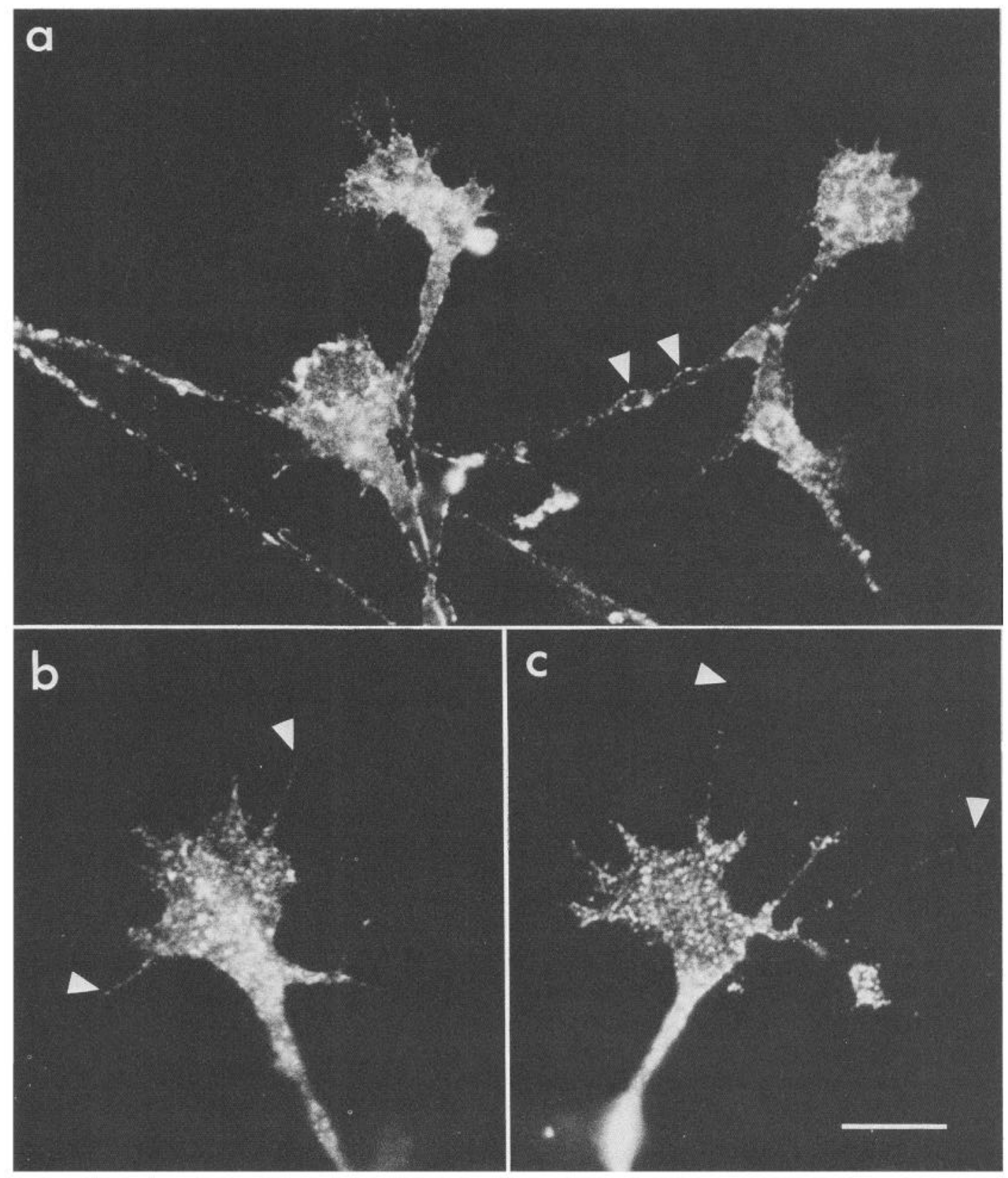

Figure 3. Anti-GAP-43 immunoreactivity of SCG neurites and growth cones. SCG neurons fixed, permeabilized, and stained after 5, 2, and $2 \mathrm{~d}$ in vitro, respectively, for $a-c$. Fluorescent photomicrograph of SCG neurites and growth cones $(a)$ shows punctate fluorescence along the distal neurites (arrowheads in $a$ ), in the body of the growth cone $(a-c)$, and reaching out to the full extent of the filopodia (arrowheads in $b, c)$. Bar, $10 \mu \mathrm{m}$.

(Fig. 6, $a, b$ ), which include Schwann cells and fibroblasts. In a pure population, Schwann cells (Fig. $6 c$ ) reacted strongly with the $217 \mathrm{C}$ antibody, a Schwann cell marker added prior to fixation (Fig. 6d), but were not labeled if they were then fixed, permeabilized, and incubated with anti-GAP-43 antibody (Fig. $6 e$ ). Similarily, fibroblasts (Fig. $6 f$ ), identified by their reaction with anti-Thy-1.1 (Fig. $6 g$ ), were not labeled by the anti-GAP43 antibody (Fig. 6h). Many of the fibroblasts in these cultures had ruffling edges that morphologially resembled growth cones (Fig. $6 f$ ), and all of these were negative for anti-GAP-43 staining (Fig. $6 h$ ). These results suggest that the GAP-43 antigens, which are not present in Schwann cells or fibroblasts, are not required by these cells even when they are performing motile functions similar to those occurring during neurite outgrowth.

\section{GAP-43 phosphorylation is stimulated by phorbol ester}

When cultures were incubated with ${ }^{32} \mathrm{P}$ orthophosphate for 1 $\mathrm{hr}$, phosphorylated proteins could be separated by 2-dimensional SDS-PAGE and detected by autoradiography of the 2-dimensional gels. One of these polypeptides migrated as expected for GAP-43; its pI was approximately 4.4, and it comigrated in the SDS-PAGE dimension, with purified GAP-43 included as a standard in a separate lane. (Although the molecular weight of GAP-43 is $24 \mathrm{kDa}$, it migrates anomalously on 


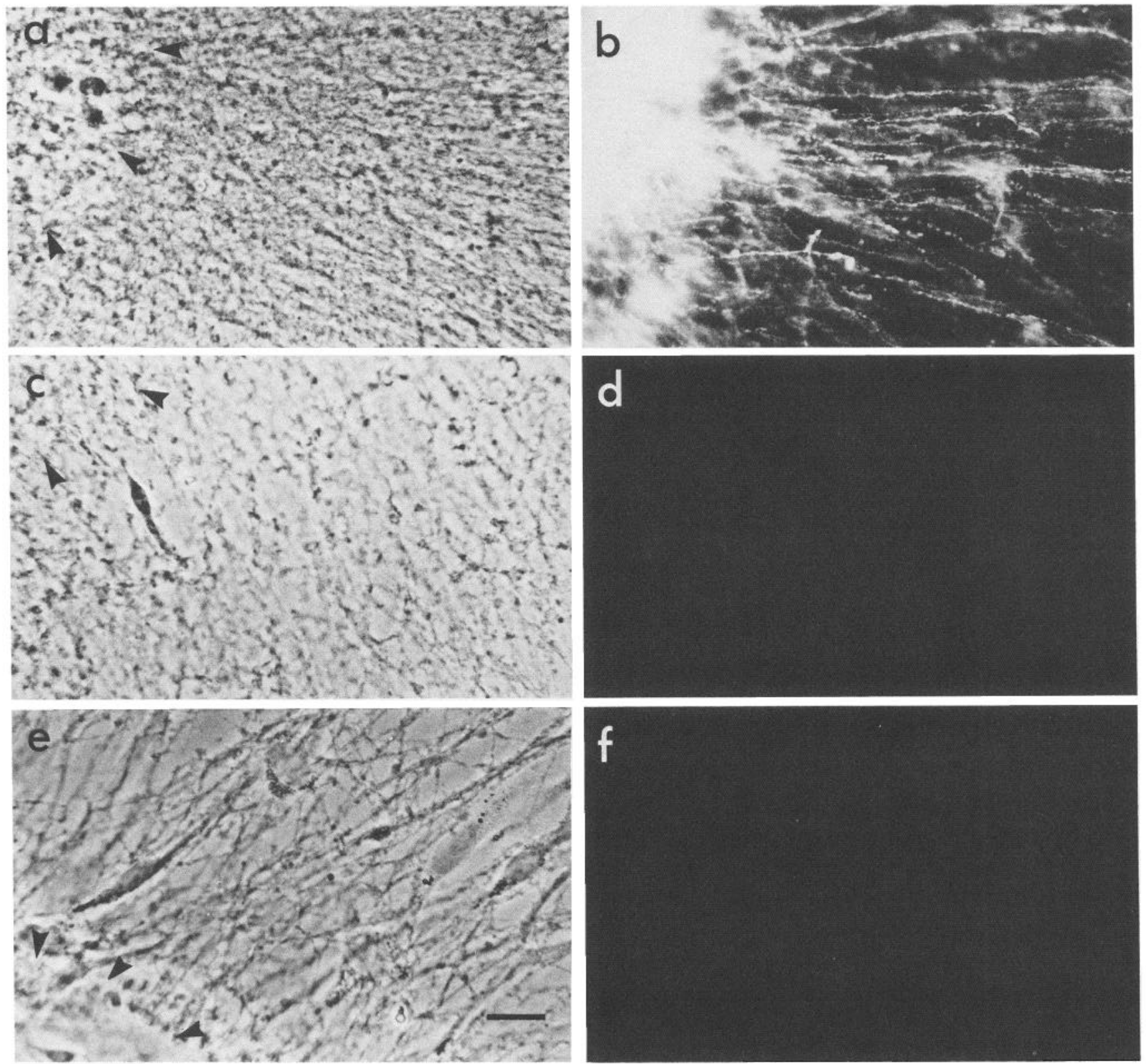

Figure 4. Surface membrane labeling of GAP-43 in SCG explant cultures. $a$, $b$, Cell surface labeling of SCG explant and neurites with A2B5, an antibody that binds to a surface ganglioside. The SCG explant and neurites seen with phase contrast $(a)$ had been incubated in A2B5 prior to fixation, and demonstrate A2B5 immunoreactivity when viewed under fluorescence $(b)$. A phase-contrast photomicrograph of a sister culture $(c)$ that had been similarly incubated in anti-GAP-43 prior to fixation shows no binding of the antibody when viewed under fluorescence $(d)$. $e, f$, An SCG explant fixed and permeabilized as a control prior to incubation in nonimmune serum for anti-GAP-43 immunostaining. No staining was present when viewed under fluorescence. The approximate edges of the explants in $a, c$, and $e$ are indicated with arrowheads. Anti-GAP-43 immunoreactivity was visualized with a fluoresceinated secondary antibody, and A2B5 immunoreactivity with a rhodaminated secondary. The cultures were used after $1 \mathrm{~d}$ in vitro. Bar, $20 \mu \mathrm{m}$.

SDS-PAGE as if its molecular weight were approximately 46 $\mathrm{kDa}$; see Benowitz et al., 1987.) When $10 \mathrm{~nm} \beta$-PMA was added to the cultures for $10 \mathrm{~min}$ after the incubation with phosphate, phosphorylation of many other proteins, including the GAP43-like protein, was greatly stimulated (Fig. $7 a$ ). By contrast, when 10 nм $\alpha$-PMA (which does not activate kinase C) or DMSO was added to the cultures in the same way, and equivalent amounts of protein analyzed by 2-dimensional SDS-PAGE, no protein, including the GAP-43 candidate, had its phosphorylation stimulated (Fig. $7 b$ ). When the spot corresponding to GAP43 was cut out of the gel, analyzed using liquid scintillation counting, and compared with the controls, phosphorylation of the GAP-43 protein had been stimulated approximately 7.3fold.

\section{Discussion}

The growth-associated protein GAP-43 is thought to be involved in axonal outgrowth (Skene and Willard, 1981a, b) and neuronal plasticity (Nelson et al., 1985). It is one of the major protein components of membranes derived from growth cones, and can be detected in growth cones of cultured embryonic DRG cells by antibody-mediated immunofluorescence (Meiri et al., 


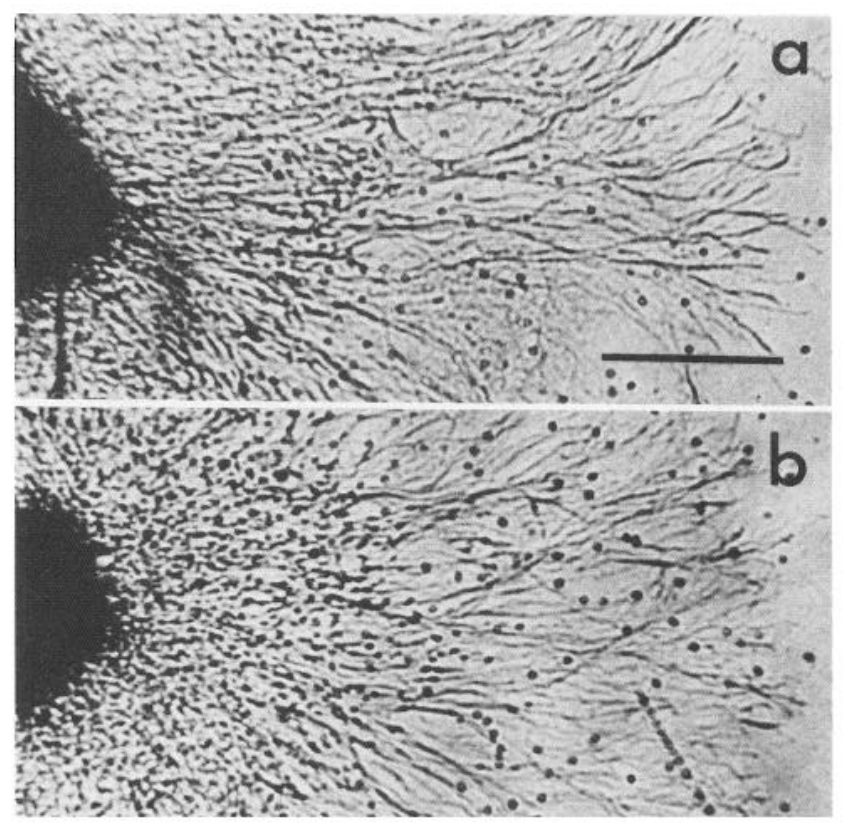

Figure 5. Explants of SCGs grown in the presence of anti-GAP-43containing media. Photomicrograph of an SCG explant grown on a collagen substrate in the presence of anti-GAP-43 $(b)$ demonstrates that the extent of neurite outgrowth does not differ from that of SCG explant grown in control media $(a)$. A portion of the explants is shown at the left. The cultures were photographed in the living state after $5 \mathrm{~d}$ in vitro. Bar, $500 \mu \mathrm{m}$.

1986). In this study we have used a culture system to analyze in detail the distribution and pattern of anti-GAP-43 immunofluorescence in regenerating sympathetic neurons. GAP-43 is located intracellularly and is membrane-associated in a punctate pattern. The antibody to GAP-43 did not react with Schwann cells or fibroblasts. Stimulation of protein kinase $C$ in the neurons resulted in stimulaton of phosphorylation of GAP-43. The current observations lead us to several considerations concerning the possible function of GAP-43 in these neurons.

When cultured SCGs from embryonic rats were grown on laminin, a 2-dimensional substrate on which neurites elongate rapidly, elaborate complex growth cone structures were easily visualized. All the neural cells, including the full extent of the growth cones, reacted with the anti-GAP-43 antibody. The nature of the reaction suggests that GAP-43 is localized intracellularly, as the present evidence has shown that only cells that were made permeable before treating them with antibody fluoresced. The faint immunoreactivity detectable in fixed, nonpermeabilized neurons is probably due to binding of the antibody to intracellular antigen exposed after disruption of the plasma membrane during the fixation process. No reactivity was detected in unfixed living neurons. These results do not rule out the possibility that extracellular epitopes of GAP-43 exist, but are only recognized by the antibody after being altered by fixation or detergent treatment. This is unlikely, however, as a recent analysis of the primary sequence of GAP-43 revealed no regions of the polypeptide chain of sufficient hydrophobicity to span the plasma membrane (Basi et al., 1987). In view of this intracellular location of GAP-43, the lack of effect on neurite outgrowth of anti-GAP-43 very likely reflects the inaccessibility of the GAP-43 antibody to GAP-43.

Cell bodies, neurites, and growth cones reacted with the an-
Table 1. Neurite growth in SCG explant cultures exposed to antiGAP-43 antibody

\begin{tabular}{lll} 
& Expt. 1 & Expt. 2 \\
\hline Control & $1766 \pm 164^{a}$ & $2214 \pm 38$ \\
Anti-GAP-43 & $2438 \pm 218$ & $2076 \pm 71$ \\
Nonimmune serum & $1854 \pm 235$ & $2365 \pm 211$
\end{tabular}

${ }^{a}$ Mean \pm SD (in $\mu \mathrm{m}$ ) of neurite extent measured from explant edge to growth cone front. All groups in both experiments had 3 explants each and were analyzed after $5 \mathrm{~d}$ in culture.

${ }^{b}$ Concentration of anti-GAP-43 was $6 \mu \mathrm{g} / \mathrm{ml}$ in experiment 1 and $60 \mu \mathrm{g} / \mathrm{ml}$ in experiment 2 .

tibody against GAP-43, but in neurons that had generated longer neurites, immunoreactivity was most concentrated in the growth cone and in the neurite immediately adjacent to it, appearing characteristically punctate in both areas. The intense fluorescence around the margins of the growth cones and adjacent neurites also suggests that GAP-43 is associated with the plasmalemma. The apparent gradient of staining with anti-GAP43 , in which neurite segments proximal to the growth cone are more fluorescent than parts of the same neurite closer to the cell soma, is consistent with the possibility that GAP-43, like other membrane proteins in growing axons, is incorporated into the plasmalemma only at the growing tip (Bray, 1970, 1973; Skene and Willard, 1981a). In this case, immunoreactivity seen in the neurite would be due to GAP-43, which was initially incorporated into the plasmalemma at the growth cone, but whose turnover was slower than the rate of outgrowth of the neurite, leaving immunoreactivity in the neurite immediately adjacent to the growth cone. Alternatively, GAP-43 could be directly incorporated into the plasmalemma of the neurite and the cell body itself. In this regard it seems unlikely that the immunoreactivity seen at the perimeter of the cell body is derived from GAP-43, which was originally inserted at the growing tip.

Because biochemical studies have shown that GAP-43 is primarily a membrane-associated protein (Skene and Willard, 1981c), the particulate appearance of the fluorescence in the body of the growth cone and along the varicosities of neurites may be due to association of GAP-43 with plasmalemma and/ or membrane-bound organelles. GAP-43 is transported rapidly down axons as part of the fast axonal transport system (Skene and Willard, 1981c), which uses membrane-bound vesicles to deliver material from its site of synthesis in the cell body (see also Pfenninger and Johnson, 1983). Because these vesicles are small (about $20-60 \mathrm{~nm}$ ), it is unlikely that the punctate fluorescence of the growth cones is due to the actual GAP-43-transporting vesicles. In preliminary results of ultrastructural studies, GAP-43 appears to be localized along the plasma membrane and in small, spherical structures within the growth cones and neurites (M. I. Johnson and P. C. Bridgman, unpublished observations). Staining at the margins of neurites and varicosities also appeared punctate, as if the membrane had been punctured by holes. Although digitonin does permeabilize membranes by selectively solubilizing the cholesterol components, the resulting membrane disruption is only apparent when viewed with electron microscopy (Fiskum et al., 1980). We cannot rule out the possibility that the punctate appearance of the neurite membranes may be generated artifactually by the paraformaldehyde fixation, but note that a similar pattern of staining was observed 

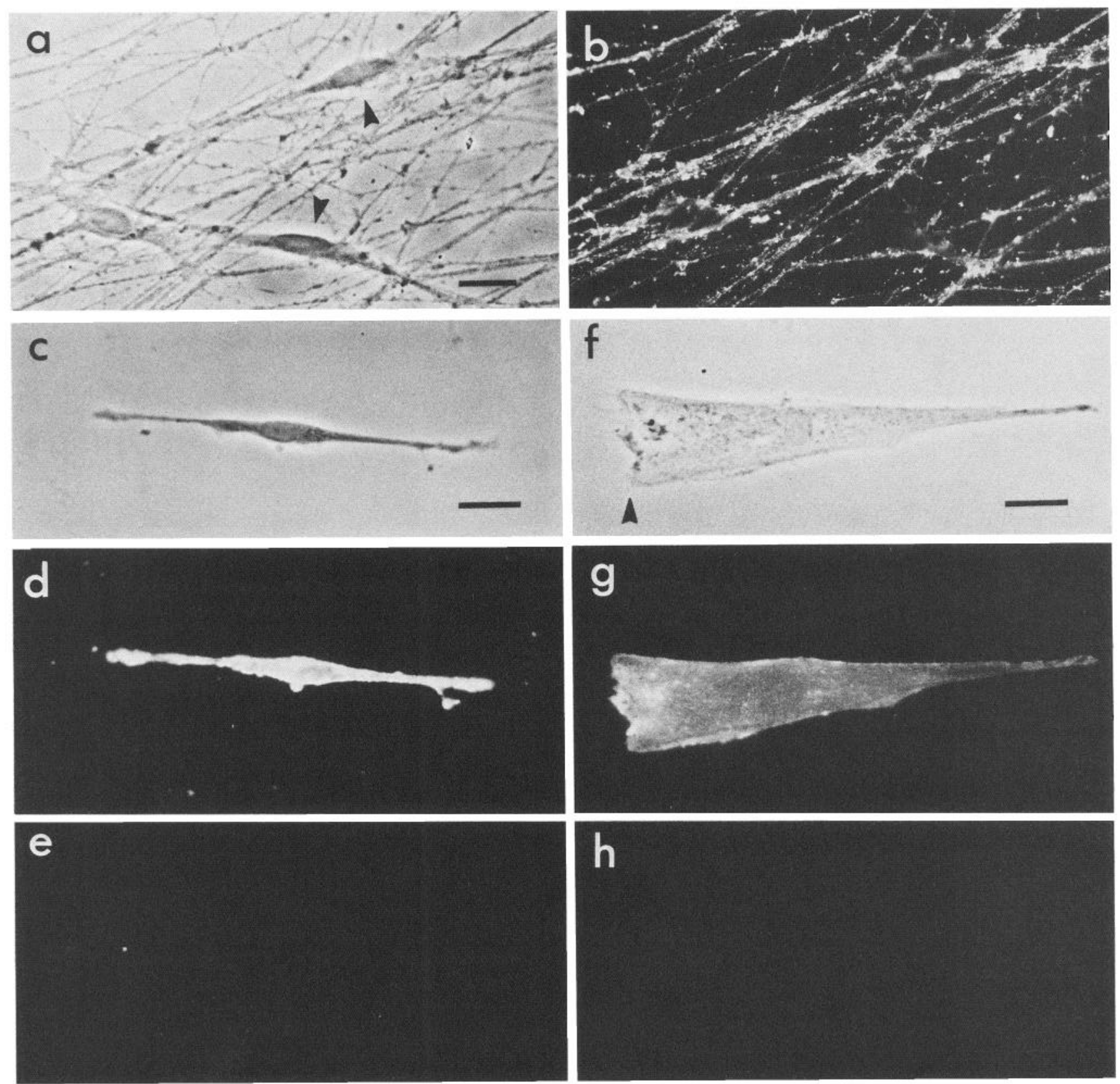

Figure 6. Anti-GAP-43 antibody does not react with Schwann cells or fibroblasts. $a, b$, Non-neuronal cells in SCG explant cultures. Phase-contrast photomicrograph (a) shows neurites extending from an SCG explant (not shown) after $3 \mathrm{~d}$ in vitro, together with 3 non-neuronal cells. The same field viewed under fluorescence microscopy $(b)$ demonstrates that the neurites, but not the non-neuronal cells, bound the antibody to GAP-43. Two of the non-neuronal cells are probably Schwann cells (arrowheads). $c-e$, A Schwann cell double-labeled with 217C and anti-GAP-43. Phasecontrast photomicrograph $(c)$ of the Schwann cell that has bound $217 \mathrm{C}(d)$, but not anti-GAP-43 $(e)$. $f-h$, A fibroblast double-labeled with antiThy-1.1. Phase-contrast photomicrograph $(f)$ of a fibroblast that bound anti-Thy-1.1 $(g)$ but not anti-GAP-43 $(h)$. The ruffling membrane of the fibroblast is to the left of the cell and is indicated with an arrowhead $(f)$. The binding of the anti-GAP-43 antibody was visualized with a fluoresceinated secondary antibody. Binding by Schwann cells and fibroblasts of $217 \mathrm{C}$ and anti-Thy-1.1, respectively, was visualized with a rhodaminated secondary antibody. Bar, $20 \mu \mathrm{m}(a, c$, and $f)$.

when methanol was used to fix the cells. In contrast, immunoreactivity within the somata of the neurons was generally diffuse, with increased fluorescence in the perinuclear area, possibly representing the association of GAP-43 with a different subcellular compartment, such as the Golgi complex during posttranslational processing.

The intense immunofluorescence in the cell bodies of dissociated SCGs that had attached to the substrate but not yet sent out neurites shows that GAP- 43 is accumulated in the cell body before neurites begin to grow. Because these embryonic SCG neurons were extending axons at the time they were transferred from the animal to the culture dish, it is likely that they were synthesizing high levels of GAP-43 before they were dissected out into culture. However, in experiments not reported here, we have observed that postnatal rat SCG neurons that had low GAP-43 immunoreactivity before they were dissociated into culture also accumulated high levels of GAP-43 in their soma prior to extending neurites in vitro. This latter observation sug- 

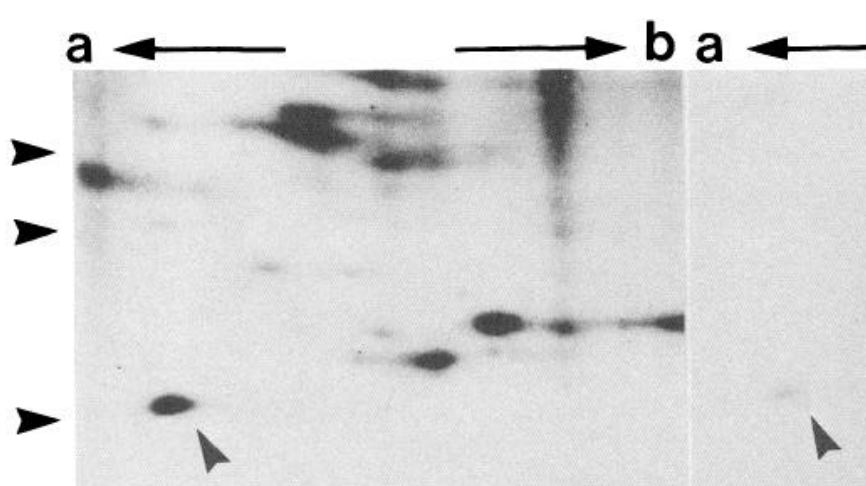

2

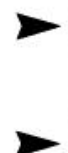

2
Figure 7. Phosphorylation of GAP-43 in SCG cultures is stimulated by phorbol ester. $a, b$, Autoradiograph of 2dimensional SDS gels of membrane proteins prepared from SCG cultures after $4 \mathrm{~d}$ in vitro. a, Autoradiograph that demonstrates that when the cultures are incubated with ${ }^{32} \mathrm{P}$ orthophosphate, followed by phorbol 12-myristate 13-acetate, phosphorylation of several proteins is stimulated. One of these (arrowhead) comigrates with GAP-43. In contrast, an autoradiograph $(b)$ from a sister culture incubated similarly with ${ }^{32} \mathrm{P}$ orthophosphate and then with $4 \alpha-$ phorbol 12,13-didecanoate shows that protein phosphorylation is significantly less apparent, and that phosphorylation of GAP-43 is not stimulated. Molecular weight standards from top of gel are 95 , $68,45,30,21$, and $14 \mathrm{kDa}$. In each case the acid end of the gel $(a \leftarrow)$ is to the left and the basic end $(\rightarrow b)$ to the right, and equivalent to $\mathrm{pH} 4.2-6.8$. gests that GAP-43 accumulation is not a consequence of axonal growth, but precedes it.

The foregoing observations lead to a consideration of the possible function of GAP-43 within neurons. The growth cone is a prominent structure in most neurons actively extending processes, and its importance in axonal growth and neural development is well-documented (see Introduction for references). The molecular mechanisms by which the growth cone accomplishes its various functions, including those of motility, adhesion, membrane addition, and guidance, are not known. Although the growing neuron does not confine GAP-43 exclusively to the growth cone, it is highly concentrated there, suggesting that it may play an important role in one or more of these functions.

Among the important functions of a growth cone is its ability to translocate across a substrate. This motility function of the growth cone is shared by other cells that have certain morphological similarities to growth cones. For example, motile fibroblasts typically form a ruffling membrane at their leading edge, reminiscent of the lamellipodia of the motile growth cone. Both cells contain actin and myosin (Letourneau, 1981), although the function of actin and myosin may differ in growth cone motility and neurite elongation (Marsh and Letourneau, 1984). These similarities suggest that certain features of the mechanism of locomotion of growth cones are shared with other motile cells. However, of the several cell types in the cultures studied here, only the neurons reacted with the anti-GAP-43 antibody (Kristjansson et al., 1982); immunocytochemically identified Schwann cells and fibroblasts did not. Moreover, because many of the nonreactive fibroblasts appeared to be motile by virtue of their characteristic ruffling edge, the current results indicate that the function performed by GAP-43 is not one required for motility in general; if, indeed, GAP-43 is involved in the process of neurite extension, it participates in an aspect of this process that is unique to neurons.
A clue to the function of GAP-43 in growth cones may be provided by the observation that it is a substrate for protein kinase C. Previous observations have indicated that GAP-43 can serve as a substrate for kinase $\mathrm{C}$ in vitro (Aloyo et al., 1983; Akers and Routtenberg, 1985; Meiri and Willard, 1986; Willard et al., 1987). When these living cultures are incubated with phorbol ester, the phosphorylation of GAP-43 is stimulated 7-fold. Kinase $\mathrm{C}$ is activated by phorbol ester entering the cells and binding to the enzyme directly (Castagna et al., 1982), circumventing the transient stimulaton of kinase $\mathrm{C}$ by diacylglycerol, which is seen when an external ligand binds to a receptor (Kaibuchi et al., 1983). Kinase C activation has been implicated in many systems in such responses as exocytosis (Pozzan et al., 1984) and regulation of actin-myosin interactions (Baraban et al., 1985), both of which may be important in growth cone function. Phorbol ester stimulation of kinase $\mathrm{C}$ has also been reported to promote neurite outgrowth in several types of neurons in tissue culture (Hsu et al., 1984), and the proteins whose phosphorylation is increased following this stimulation have been described (Burgess et al., 1986). Here we have shown that one of the proteins that is most highly phosphorylated when SCG cultures are treated with phorbol ester is GAP-43, which is a kinase $C$ substrate in vitro (Akers and Routtenberg, 1985; Meiri and Willard, 1986). The identification of GAP-43 as a major substrate of protein kinase $\mathrm{C}$ in living sympathetic neurons suggests that GAP-43 may be an element of, or may be regulated by, a transduction system that enables the growth cone to sample the environment and then to generate an internal response to these external signals (for example, in Gundersen and Barrett, 1980; Gundersen, 1985). One specific possibility is suggested by the punctate distribution of GAP-43 in the growth cone. If these concentrations of GAP-43 corresponded to points of adhesion of the growth cone to the substrate, the GAP-43 might function to modulate the adhesion of different sites on the growth cone in response to extracellular signals. It is also 
possible that this may involve the internal rcorganization of the cytoskeleton of the growth cone, as well as modulate the sites of membrane addition.

In conclusion, the observations reported here demonstrate that the neuron-specific protein, GAP-43, is a component of the soma, neurite, and growth cone of sympathetic neurons that are regenerating axons in culture, and that within these neurons, GAP-43 is a major substrate for kinase C. Its concentration in the growth cone may explain its increased synthesis in neurons with growing axons. Its location and phosphorylation by kinase $C$ suggests that it could perform a function in the growth cone that is modulated by external signals, such as those used in pathfinding or in the control of axonal elongation. For example, GAP-43 could be an element of a signal-transduction system involving extracellular ligands, receptors, and kinase $\mathrm{C}$.

\section{References}

Akers, R. F., and A. Routtenberg (1985) Protein kinase C phosphorylates a $47 \mathrm{Mr}$ protein (F1) directly related to synaptic plasticity. Brain Res. 344: 147-151.

Aloyo, V. J., H. Zwiers, and W. H. Gispen (1983) Phosphorylation of B-50 protein by calcium-activated, phospholipid-dependent protein kinase and B-50 protein kinase. J. Neurochem. 41: 649-653.

Argiro, V., and M. I. Johnson (1982) Patterns and kinetics of neurite extension from sympathetic neurons in culture are age dependent. $J$. Neurosci. 2: 503-512.

Argiro, V., M. B. Bunge, and M. I. Johnson (1984) Correlation between growth cone form and movement and their dependence on neuronal age. J. Neurosci. 4: 3051-3062.

Baraban, J. M., R. J. Gould, S. J. Peroutka, and S. H. Snyder (1985) Phorbol ester effect on neurotransmission: Interaction with neurotransmitters and calcium in smooth muscle. Proc. Natl. Acad. Sci. USA 82: 604-607.

Basi, G. S., I. V. Jacobson, J. Schilling, and J. H. P. Skene (1987) Primary structure and transcriptional regulation of GAP-43, a protein associated with nerve growth. Cell 49: 785-791.

Bastiani, M. J., and C. S. Goodman (1986) Guidance of neuronal growth cones in the grasshopper embryo. III. Recognition of specific glial pathways. J. Neurosci. 6: 3532-3541.

Benowitz, L. I., N. I. Perrone-Bizzozero, and S. P. Finklestein (1987) Molecular properties of the growth-associated protein GAP-43 (B-50). J. Ncurochcm. 48: 1640-1647.

Bentley, D., and A. Toroian-Raymond (1986) Disoriented pathfinding by pioneer neurone growth cones deprived of filopodia by cytochalasin treatment. Nature 323: 712-715.

Bray, D. (1970) Surface movements during the growth of single explanted neurons. Proc. Natl. Acad. Sci. USA 65: 4516-4519.

Bray, D. (1973) Branching patterns of isolated sympathetic neurons. J. Cell Biol. 56: 702.

Bray, D., and K. Chapman (1985) Analysis of microspike movements in the neuronal growth cone. J. Neurosci. 5: 3204-3213.

Bunge, M. B. (1973) Fine structure of nerve fibers and growth cones of isolated sympathetic neurons in culture. J. Cell Biol. 56: 713-735.

Bunge, M. B., M. I. Johnson, and V. J. Argiro (1983) Studies of regenerating nerve fibers and growth cones. In Spinal Cord Regeneration, C. C. Kao, R. P. Bunge, and P. J. Rcicr, cds., pp. 99-120, Raven, New York.

Bunge, M. B., M. I. Johnson, M. D. Ard, and N. Kleitman (1987) Factors influencing the growth of regenerating nerve fibers in culture. Prog. Brain Res. 71: 61-74.

Burgess, S. K., N. Sahyoun, S. G. Blanchard, H. LeVine III, K.-J. Chang and P. Cuatrecasas (1986) Phorbol ester receptors and protein kinase $\mathrm{C}$ in primary neuronal cultures: Development and stimulation of endogenous phosphorylation. J. Cell Biol. 102: 312-319.

Castagna, M., Y. Takai, K. Kaibuchi, K. Sano, U. Kikkawa, and Y. Nishizuka (1982) Direct activation of calcium-activated, phospholipid-dependent protein kinase by tumor-promoting phorbol ester. J. Biol. Chem. 257: 7847-7851.

Caudy, M., and D. Bentley (1986) Pioneer growth cone steering along a series of ncuronal and non-ncuronal cues of different affinities. $J$. Neurosci. 6: 1781-1795.
Eisenbarth, G. S., F. S. Walsh, and M. Nirenberg (1979) Monoclonal antibody to a plasma membrane antigen of neurons. Proc. Natl. Acad. Sci. USA 76: 4913-4917.

Fiskum, G., S. W. Craig, G. L. Decker, and A. L. Lehninger (1980) The cytoskeleton of digitonin-treated rat hepatocytes. Proc. Natl. Acad. Sci. USA 77: 3430-3434.

Gundersen, R. W. (1985) Sensory neurite growth cone guidance by substrate adsorbed nerve growth factor. J. Neurosci. Res. 13: 199212.

Gundersen, R. W., and J. N. Barrett (1980) Characterisation of the turning response of dorsal root neurites towards nerve growth factor. J. Cell Biol. 87: 546-554.

Hammarback, J. A., and P. C. Letourneau (1986) Neurite extensions across regions of low cell-substratum adhesivity: Implications for the guidepost hypothesis of axonal pathfinding. Dev. Biol. 117:655-662.

Harrison, R. G. (1907) Observations on the living developing nerve fibre. Anat. Rec. $1: 116-118$.

Hsu, L., D. Natyzak, and J. D. Laskin (1984) Effects of the tumor promoter 12-O-tetradecanoylphorbol-13-acetate on neurite outgrowth from chick embryonic sensory ganglia. Cancer Res. 44: 46074614

Johnson, M. I., and V. Argiro (1983) Techniques in the tissue culture of rat sympathetic neurons. Methods Enzymol. 103: 334-347.

Johnston, R. N., and N. K. Wessells (1980) Regulation of the elongating nerve fiber. In Current Topics in Developmental Biology, vol. 16, R. Kevin Hunt, ed., pp. 165-206, Academic, New York.

Kaibuchi, K., Y. Takai, M. Sawamura, M. Hoshijima, T. Fujikura, and Y. Nishizuka (1983) Synergistic functions of protein phosphorylation and calcium mobility in platelet function. J. Biol Chem. 258: 6701.

Karns, L. R., S.-C. Ng, J. A. Freeman, and M. C. Fishman (1987) Cloning of complementary DNA for GAP-43, a neuronal growthrelated protein. Science 236: 597-600.

Kater, S., and P. Letourneau (eds.) (1985) Biology of the Nerve Growth Cone. J. Neurosci. Res. 13 (special issue).

Kristjansson, G. I., H. Zwiers, A. B. Oestreicher, and W. H. Gispen (1982) Evidence that the synaptic phosphoprotein B-50 is localized exclusively in nerve tissue. J. Neurochem. 39: 371-378.

Kuwada, J. Y. (1986) Cell recognition by neuronal growth cones in a simple vertebrate embryo. Science 233: 740-746.

Landis, S. C. (1983) Neuronal growth cones. Annu. Rev. Physiol. 45: 567-580.

Letourneau, P. C. (1975) Cell-to-substratum adhesion and guidance of axonal elongation. Dev. Biol. 44: 92-101.

Letourneau, P. C. (1981) Immunocytochemical evidence for colocalization in neurite growth cones of actin and myosin and their relationship to cell-substratum adhesions. Dev. Biol. 85: 113-122.

Letourneau, P. C. (1985) Axonal growth and guidance. In Molecular Bases of Neural Development, G. M. Edelman, ed., pp. 269-293, Wiley, New York.

Marsh, L., and P. C. Letourneau (1984) Growth of neurites without filopodial or lamellipodial activity in the presence of cytochalasin B. J. Cell Biol. 5: 2336-2344.

Marshak-Rothstein, A., P. Fink, T. Gridley, D. H. Raulet, M. J. Bevan, and M. L. Gefter (1979) Properties and applications of monoclonal antibodies directed against determinants of the Thy-1 locus. J. Immunol. 122: 2491-2497.

Meiri, K. F., and M. Willard (1986) Autophosphorylation of GAP43 , a protein associated with axon growth. Soc. Neurosci. Abstr. 12: 500.

Meiri, K. F., K. H. Pfenninger, and M. B. Willard (1986) Growthassociated protein, GAP-43, a polypeptide that is induced when neurons extend axons, is a component of growth cones and corresponds to $\mathrm{pp} 46$, a major polypeptide of a subcellular fraction enriched in growth cones. Proc. Natl. Acad. Sci. USA 83: 3537-3541.

Nelson, R. B., A. Routtenberg, C. Hyman, and K. H. Pfenninger (1985) A phosphoprotein (F1) directly related to neural plasticity in adult brain may be identical to a major growth cones membrane protein (pp46). Soc. Neurosci. Abstr. 11: 927.

Peng, W., J. P. Bresselr, E. Tiffany-Castiglioni, and J. de Vellis (1982) Development of a monoclonal antibody against a tumor-associated antigen. Science 215: 1102-1104.

Pfenninger, K. H., and M. P. Johnson (1983) Membrane biogenesis in the sprouting ncuron. I. Sclective transfer of newly synthesized phospholipid into the growing neurite. J. Cell Biol. 87: 1038-1042. 
Pfenninger, K. H., and M.-F. Maylie-Pfenninger (1981a) Lectin labeling of sprouting neurons. I. Regional distribution of surface glycoconjugates. J. Cell Biol. 89: 536-546.

Pfenninger, K. H., and M.-F. Maylie-Pfenninger (1981b) Lectin labeling of sprouting neurons. II. Relative movement and appearance of glycoconjugates during plasmalemmal expansion. J. Cell Biol. 89: 547-559.

Pomerat, C. M., W. J. Hendleman, C. W. Raiborn, and J. F. Massey (1967) Dynamic activities of nervous tissue in vitro. In The Neuron, H. Hyden, ed., pp. 119-178, Elsevier, New York.

Porter, S., M. B. Clark, L. Glaser, and R. P. Bunge (1986) Schwann cells stimulated to proliferate in the absence of neurons retain full functional capability. J. Neurosci. 6: 3070-3078.

Pozzan, T., G. Gatti, N. Duzio, L. M. Vincenti, and J. Meldolesi (1984) $\mathrm{Ca}^{2+}$-dependent and independent release of neurotransmitters from PC12 cells: A role for protein kinase $\mathrm{C}$ activation? J. Cell Biol. 99: 628-638.

Ramon y Cajal, S. (1890) A quelle epoque apparaissent les expensions des cellules nerveuses de la moelle epinere du poulet? Anat. Anz. 5: 609-613.

Ranscht, B., D. J. Moss, and C. Thomas (1984) A neuronal surface glycoprotein associated with the cytoskeleton. J. Cell Biol. 99: 18031813.

Skene, J. H. P., and M. Willard (1981a) Changes in axonally transported proteins during axon regeneration in toad retinal ganglion cells. J. Cell Biol. 89: 86-95.
Skene, J. H. P., and M. Willard (1981b) Axonally transported proteins associated with axon growth in rabbit central and peripheral nervous system. J. Cell Biol. 89: 96-103.

Skene, J. H. P., and M. Willard (1981c) Electrophoretic analysis of axonally Iransported proteins in toad retinal ganglion cells. J. Neurochem. 37: 79-87.

Skene, J. H. P., R. D. Jacobson, G. J. Snipes, C. B. McGuire, J. Norden, and J. A. Freeman (1986) A protein induced during nerve growth, GAP-43 is a major component of growth-cone membranes. Science 233: 783-785.

Talian, J. C., J. B. Olmstead, and R. D. Goldman (1984) A rapid procedure for preparing fluorescein-labelled specific antibodies from whole serum: Its use in analysing cytoskeletal architecture. J. Cell Biol. 97: 1277-1282.

Tosney, K. W., and N. K. Wessels (1983) Neuronal motility: The ultrastructure of veils and microspikes correlates with their motile activities. J. Cell Sci. 61: 389-411.

Wilchek, M., T. Miron, and J. Kohn (1984) Affinity chromatography. Methods Enzymol. 104: 3-21.

Willard, M., K. F. Meiri, and M. I. Johnson (1987) The role of GAP43 in axon growth. In Axonal Transport, R. S. Smith and M. A. Bishop, eds., pp. 407-420, Liss, New York.

Yamada, K. M., B. S. Spooner, and N. K. Wessells (1971) Ultrastructure and function of growth cones and axons of cultured nerve cells. J. Cell Biol. 49: 614-635. 